then he wakes before he wets; and finally, if all goes well, he sleeps through the night without waking or wetting. The process is not completely understood, but it has repeatedly been shown that with the electric alarm some three quarters of enuretics over 7 years of age can become dry, even though in a third of these the treatment will need to be repeated. The apparatus should not, however, be prescribed like a packet of aspirins. It should be used as one part of a comprehensive approach that considers the child in his environment. The doctor should understand the way the alarm apparatus works and he needs to explain it clearly and convincingly to parents and child. He will get the best results if he is not only an expert and enthusiast but a good communicator as well.

\footnotetext{
1 Kolvin, I., Mac Keith, R. C., and Meadows, S. R., in Clinics in Developmental Medicine, nos. 48-49. London, Heinemann, 1973.

2 Forsythe, W. I., and Redmond, A., Archives of Disease in Childhood, 1974, $49,259$.

${ }^{3}$ Blackwell, B., and Currah, J., in Bladder Control and Enuresis, Clinics in Developmental Medicine, nos. 48-49. London, Heinemann, 1973.

4 Meadow, R., Archives of Disease in Childhood, 1974, 49, 257.

Dische, S., in Bladder Control and Enuresis, Clinics in Developmental Medicine, nos. 48-49. London, Heinemann, 1973.
}

\section{Migraine Clinics}

Specialist migraine clinics have grown in number since 1955, when Macdonald Critchley opened the first in Britain at King's College Hospital and the National Hospital, Queen's Square. In most of them the patients are seen by appointment between attacks; but in 1969 a new approach was tried when the City Migraine Clinic was opened under the aegis of St. Bartholomew's Hospital. Here sufferers could seek help while having an attack.

If quantity is any indication of success, then during its first four years this clinic treated 2,000 patients during an attack and another 6,000 referred by physicians. Recently the clinic moved to larger premises in order to cope with increasing numbers and changed its name to the Princess Margaret Migraine Clinic. Other clinics, too, have more than enough patients, with waiting lists of several weeks. What benefit does the patient derive?

During an attack patients are given the use of a couch and analgesic and anti-emetic tablets, which enable most of them to sleep an attack off and then go home by themselves some three to four hours later. There is no doubt in the patient's mind that this treatment is preferable to having to travel home by public transport struggling with nausea and headache.

Between attacks all migraine clinics provide a consultative service similar to that given by a general physician or neurologist. An appointment system allows 20-30 minutes for the initial consultation. Because there is no specific test or investigation that can establish the diagnosis, the doctor must rely on clinical judgement, based on a detailed history and a full physical examination showing no abnormality.

Medical staff at such a clinic soon acquire specialized knowledge of uncommon manifestations and complications such as status migrainosus. The time available for the consultation is adequate to ferret out the specific anxiety aroused in the patient's mind by severe or repeated attacks - a tumour, an impending cerebrovascular catastrophe, or insanity being common fears. A complete history will elicit physiological factors-dietary, hormonal, physical, and sleep-that may provoke attacks in that individual rather than attributing all migraines to "stress." Once the precipitants have been found the patient can be advised to adopt a positive prophylactic approach.
The patient rapidly senses that the physician to whom he is talking "knows all about it." The patient is grateful to the doctor who shows his interest-often the direct result of research in progress at the clinic. Most sufferers willingly co-operate in research projects, and if asked will readily agree to provide urine or blood samples or keep records and reattend.

Though service to the patient is the physician's first duty, research is a vital adjunct to the function of a migraine clinic. There is no animal model; drug trials can be carried out only on human beings; and a large series of patients having frequent attacks will produce an answer within months rather than years. With sufficient numbers, hypotheses can be tested. Whether these hypotheses are biochemical, pharmacological, physical, or psychological is immaterial, provided they are scientifically tested and the results, even if negative, are written up, saving other research workers needless repetition.

\section{Demand and the N.H.S.}

With the Prime Minister's recognition last week that inflation affects medicine like everything else, the prospect of immediate bankruptcy for the N.H.S. has receded. The delegation of nurses, midwives, doctors, and dentists (see p. 424) that went to Downing Street was able to present convincing evidence that extra money had to be found simply to enable the service to maintain its current shaky status. In simple terms, since the N.H.S. costs about $£ 3,000$ million a year then $15-20 \%$ inflation adds $£ 450-600$ million to the bill. To that must be added the money that will be needed to pay for the relatively large pay increases that seem likely to be awarded to nurses, radiographers, and other N.H.S. workers who have fallen so far behind in the national pay scramble. The Government's pledge that extra money will be found for these pay awards gives the N.H.S. a welcome breathing space.

The larger question remains unanswered, however-and indeed the delegation failed to persuade the Prime Minister that it ought even to be asked. What is to be the future pattern of control over N.H.S. income and expenditure? More and more people are beginning to appreciate the force of $\mathrm{Mr}$. Enoch Powell's argument ${ }^{1}$ that there is no limit to the growth in demand in a free N.H.S. Each year sees new technological advances in medical care, so that common conditions become more expensive to treat. Compare the cost of treating a coronary or osteoarthritis of the hip now with that a decade ago; and the same pattern is being repeated over the whole range of medicine. Children with haemophilia, for example, could now be given prophylactic treatment with factor VIII and so be protected against the pain and misery of haemorrhage into their joints-but apparently the extra $£ 2$ million a year that would be needed cannot be found out of current allocations. $^{2}$

Perhaps Ivan Illich is right, in his book published here last week, ${ }^{3}$ and medicine has passed a watershed; perhaps it is no longer self-evident that all its advances have desirable effects that can be verified and measured. ${ }^{4}$ The problem is certainly not confined to Britain or to the N.H.S. - though its method of financing adds another dimension. The current crisis should start us all thinking about the sort of medical care that society can afford and whose responsibility it is to ask and whose to answer that question.

\footnotetext{
1 Powell, J. E., Medicine and Politics. London, Pitman, 1966.

2 Biggs, R., Lancet, 1974, 1, 1339

\& Billich, I., Tools for Conviviality. London, Calder and Boyars, 1974 price 95 p.
ch, I. Lancet, 1974, 1, 918. 